DOI: https://doi.org/10.47405/mjssh.v6i8.959

\begin{tabular}{|c|c|}
\hline 4 & Malaysian Journal of Social Sciences and Humanities (MJSSH) \\
\hline $\begin{array}{l}\text { Malaysian Juoural of } \\
\text { Social ccciecces and }\end{array}$ & Volume 6, Issue 8, August 2021 \\
\hline (MJ-sSH) & e-ISSN : 2504-8562 \\
\hline & $\begin{array}{l}\text { Journal home page: } \\
\text { www.msocialsciences.com }\end{array}$ \\
\hline
\end{tabular}

\title{
Sistem Pementoran Berstrategi di kalangan Staf Akademik PPD SPACE UTM
}

\author{
Yusmady Md Junus ${ }^{1}$, Siti Nurhuda Abd Wahid ${ }^{1}$, Abdul Qayyum Nazri' ${ }^{1}$, Nabilah Hanim Mohd Anuar' ${ }^{1}$, \\ Nazriah Rasul' ${ }^{\text {, Noralvina Nazri1 }}{ }^{\text {, Rafiza Mohamed }}{ }^{1}$ \\ 1Pusat Pengajian Diploma SPACE, Universiti Teknologi Malaysia (UTM)
}

Correspondence: Yusmady Md Junus (yusmady.kl@utm.my)

\begin{abstract}
Abstrak
Kajian ini dijalankan bertujuan membina satu sistem pementoran secara berstrategi untuk diguna pakai dan mengenal pasti tahap kesediaan staf akademik di PPD SPACE UTM terhadap sistem ini. Banyak kepentingan dan faedah sistem pementoran kepada staf akademik dan organisasi terutamanya dari segi kenaikan pangkat, pengurusan bakat dan lain-lain. Kajian ini melibatkan 87 responden daripada 94 populasi staf akademik di PPD SPACE UTM di Kampus Kuala Lumpur dan Johor Bahru. Data telah dikumpulkan melalui instrumen borang soal selidik yang telah diedarkan kepada semua staf akademik. Hasil daripada kajian literatur yang telah dilaksanakan, satu sistem pementoran berstrategi telah dibangunkan iaitu objektif kajian pertama. Bagi objektif kedua, analisis kajian mendapati bahawa 97.70\% staf akademik bersedia menerima pelaksanaan pementoran berstrategi. Didapati bahawa, faktor kepentingan sistem mentor-menti yang utama kepada staf akademik adalah dapat meningkatkan keberkesanan pengajaran, penyelidikan dan perkembangan profesional iaitu 56.32\%. Manakala $28.74 \%$ menyatakan pementoran menyokong prestasi kenaikan pangkat di kalangan staf dan $5.75 \%$ menyatakan ia meningkatkan minat dalam kerjaya akademik. Dan masing-masing $4.60 \%$ berpendapat faedah kepentingan sistem pementoran ini dapat mempromosikan perkembangan kerjaya dan kepuasan serta $4.60 \%$ lagi menyatakan ia dapat meningkatkan produktiviti PPD SPACE UTM. Kesimpulannya, terdapat banyak kepentingan yang boleh diperoleh dari sistem pementoran berstrategi ini. Sokongan dan komitmen daripada staf akademik dan pihak pengurusan tertinggi UTMSPACE adalah diperlukan bagi menjayakan program pementoran berstrategi di peringkat PPD SPACE UTM dan seterusnya dikembangkan di peringkat UTMSPACE secara keseluruhannya.
\end{abstract}

Kata kunci: pementoran, mentor, menti, akademia, pendidikan tinggi

\section{Strategic Mentoring System Among Academic Staff of PPD SPACE UTM}

\begin{abstract}
This study was conducted to build a strategic mentoring system to be used and identify the level of readiness of academic staff at PPD SPACE UTM to this system. There are many importance and benefits of mentoring system to academic staff and organizations especially in terms of promotion, talent management and others. This study involved 87 respondents from 94 academic staff population at PPD SPACE UTM in Kuala Lumpur and Johor Bahru Campuses. Data were collected through a questionnaire form instrument that was distributed to all academic staff. As a result of the literature review that has been carried out, a strategic mentoring system has been developed which is the objective of the first study. For the second objective, the analysis of the study found that $97.70 \%$ of academic staff were willing to accept the implementation of strategic mentoring. It was found that the
\end{abstract}


main factor of importance of the mentoring system to the academic staff is to increase the effectiveness of teaching, research and professional development which is $56.32 \%$. While $28.74 \%$ stated that mentoring supports promotion performance among staff and 5.75\% stated that it increases interest in academic careers. And each $4.60 \%$ think the benefits of the importance of this mentoring system can promote career development and satisfaction and another $4.60 \%$ stated that it can increase the productivity of PPD SPACE UTM. In conclusion, there are many benefits to be gained from this strategic mentoring system. Support and commitment from academic staff and the top management of UTMSPACE is required for the success of the strategic mentoring program at the PPD SPACE UTM level and subsequently developed at the UTMSPACE level as a whole.

Keywords: mentoring, mentor, mentee, academia, higher education

\section{Pengenalan}

Pementoran ditakrifkan sebagai satu proses di mana individu yang lebih berpengalaman bertindak sebagai kaunselor, pembimbing, tutor atau jurulatih kepada individu yang tidak berpengalaman dalam sesuatu bidang tertentu (Rekha \& Ganesh, 2012, Azman et al., 2007 \& Kram, 1985). Pementoran digunakan untuk menerangkan perhubungan dimana seseorang individu menerima nasihat, bimbingan khusus atau bantuan daripada penasihat yang lebih berpengalaman. Mentor adalah "seseorang yang akan membantu menti dalam mereflek, merancang dan menguruskan strategi kerjaya (Nakamura \& Shernoff, 2009). Fokus utama seorang mentor adalah "membantu, membangunkan menti dengan menyediakan sokongan dari segi kerjaya dan psikososial (Young \& Perrewa, 2000, Scandura \& Williams, 2004; Sawatzky \& Enns, 2009). Mentor terdiri daripada pensyarah kanan yang lebih berpengalaman yang akan berkongsi pengetahuan dan kepakaran dengan menti dalam membuat satusatu keputusan (Debowski, 2012).

Definisi mentor adalah “...satu proses bimbingan dan merupakan kerangka atau panduan untuk kepimpinan bagi bidang profesional dan akademik yang lebih efektif" (Aladejana et al., 2006). Selain itu, pementoran juga dikatakan sebagai satu "...proses yang melibatkan seorang individu (mentor) yang berpengalaman, dipandang tinggi, dan memahami membimbing seorang individu lain (menti) dalam perkembangan dan pemeriksaan melalui penilaian mereka sendiri, pembelajaran dan peribadi dan perkembangan profesional. Mentor kebiasaannya, tapi tidak semestinya, bekerja di dalam organisasi atau bidang yang sama seperti mentinya, membantu dengan mendengar dan bercakap dengan yakin kepada mentinya" (Watkins \& Whalley, 1993).

Pementoran yang berkesan mempunyai dua (2) elemen yang sangat penting iaitu komunikasi bersemuka dan komunikasi terbuka (Bernier et al., 2005; Azman et al., 2007). Sistem pementoran dalam konteks universiti, komunikasi bersemuka ditakrifkan sebagai interaksi atau hubungan secara langsung antara pihak pemberi sumber dan pihak penerima sumber tanpa menggunakan perantaraan saluran yang dilaksanakan dalam masa yang sama. Manakala komunikasi terbuka di mana individu boleh mengutarakan pandangan atau persoalan secara terbuka. Dalam organisasi, pementoran secara umumnya ditakrifkan sebagai pekerja yang berpengalaman menjadi contoh atau teladan, memberi bimbingan dan didikan kepada menti. Pementoran memberi kesan yang positif kepada pembangunan kerjaya dan interpersonal menti dalam pekerjaan mereka (Kram, 1985; Anderson \& Shannon, 1988). Ia juga bertindak sebagai alat untuk membina potensi individu atau kumpulan dalam melaksanakan tanggungjawab atau mempelajari perkara yang baru (Aishah \& Nurul, 2020).

Northcott (2000), Oliver dan Aggleton (2003) menyatakan bahawa atribut pementoran adalah (a) memberikan bimbingan, memberikan sokongan, dan bantuan secara profesional oleh mentor. Manakala atribut bagi mentor pula adalah (a) staf akademik kanan, (b) lebih berpengalaman, dan (c) boleh dijadikan contoh ikutan (role model). Dan atribut bagi menti pula adalah (a) dibantu oleh mentor dalam proses perhubungan, dan (b) memerlukan bantuan dalam pembangunan diri, PdP, penyelidikan, perundingan dan kepimpinan akademik. Model Kemahiran Mentor yang telah diperkenalkan oleh Young dan Perrewe (2000) yang menyatakan bahawa kemahiran khusus menti adalah pantas belajar, 
menunjukkan inisiatif, mendengar dengan minda terbuka, mengikut keseluruhan proses dan menjaga perhubungan. Manakala kemahiran khusus mentor pula adalah memberi peluang, membina keupayaan, memberi maklum balas yang membina, memantau dan bertanggungjawab ke atas matlamat menti dan berinspirasi. Namun begitu, mentor dan menti perlu mempunyai kemahiran yang sama dari segi mendengar secara aktif, menyediakan matlamat kerjaya, membina kepercayaan, memberikan galakan dan mempunyai 'sense of humor'.

Bagi seorang mentor, ia merupakan peluang untuk membangunkan kedua-dua kompetensi peribadi dan profesional manakala bagi seorang menti, ia ada peluang untuk belajar daripada seseorang yang lebih baik dan berpengalaman. Lazimnya, perhubungan ini berakhir dengan tahap perhubungan akrab antara rakan sekerja dalam sesebuah organisasi. Pementoran ini dilaksanakan sebagai satu program latihan dan pendidikan yang berstrategi untuk membangunkan potensi pensyarah muda yang kurang pengalaman, pendedahan dan kemahiran. Program pementoran ini diharap dapat menjadi platform untuk bimbingan dan kerangka kepimpinan bidang profesional dan akademik yang lebih efektif seterusnya meningkatkan kompetensi pensyarah muda. Empat (4) teras utama dalam program pementoran telah dikenal pasti iaitu (a) Pengajaran dan Pembelajaran (PdP) termasuk Penasihat Akademik; (b) Penyelidikan, termasuk Penulisan dan Penerbitan; (c) Perundingan dan Khidmat Masyarakat; dan (d) Kepimpinan Akademik. Program ini diwujudkan untuk meningkatkan prestasi pensyarah muda melalui beberapa langkah utama: (a) Pemadanan mentor dan menti yang bersesuaian; (b) Pertemuan berkala antara mentor dan menti mengikut kesesuaian; (c) Penilaian berkala terhadap prestasi mentor-menti berpandukan matlamat yang ditetapkan; dan (d) Maklum balas konstruktif yang berkesan daripada mentor dan menti.

\section{Metod Kajian}

Bagi memastikan kajian ini berjaya terdapat dua (2) metodologi yang akan diguna pakai. Kaedah yang pertama ialah kajian literatur dijalankan kepada model pementoran dari pelbagai sumber. Adaptasi sistem pementoran daripada universiti-universiti terkemuka dilakukan mengikut kesesuaian suasana dan persekitaran. Bagi mencapai objektif kedua, kaedah soal selidik digunakan untuk mengumpulkan data tahap persediaan daripada staf akademik di PPD SPACE UTM. Rujuk Rajah 1.

\section{Rajah 1: Metod Kajian}

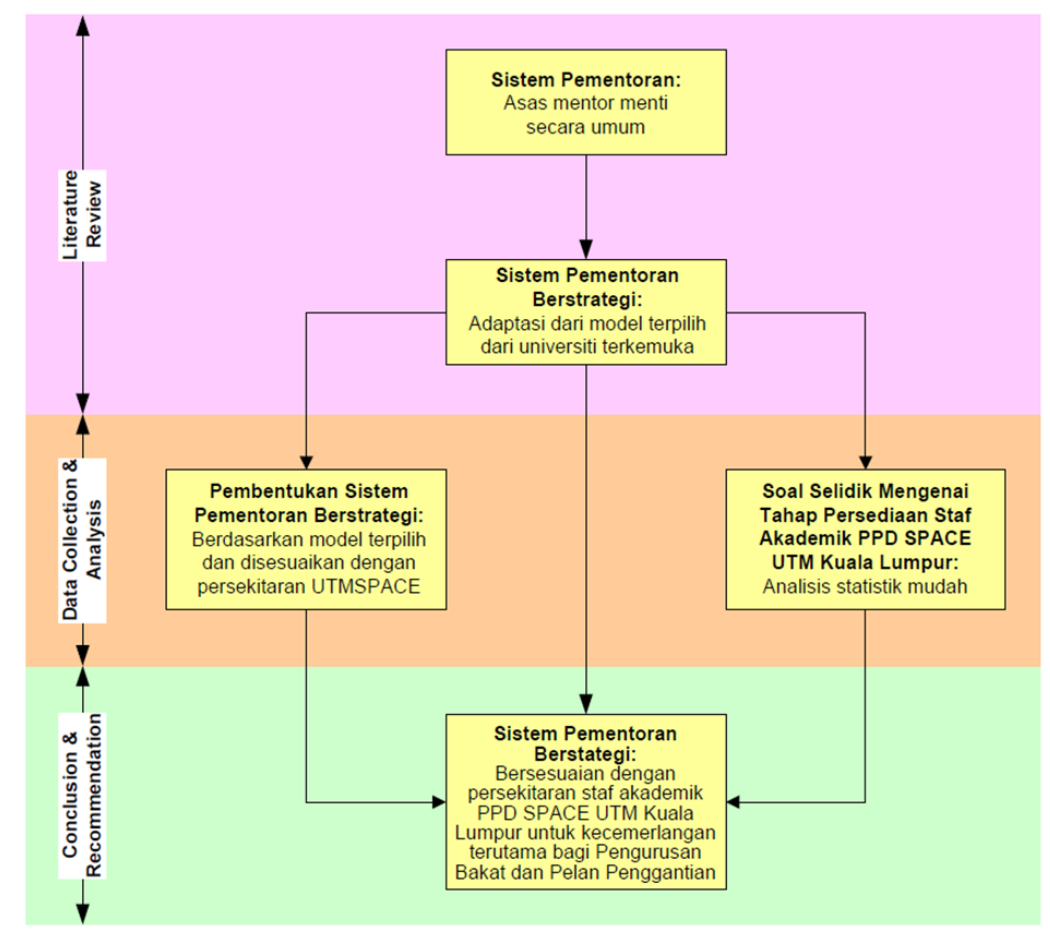

Hasil dan Perbincangan Kajian 
Bagi objektif pertama kajian, satu sistem pementoran berstrategi telah dibangunkan mengikut keperluan dan acuan PPD SPACE UTM. Ia bermula dengan organisasi pelaksana bagi sistem ini, iaitu bermula daripada pihak pengurusan tertinggi hingga ke peringkat jabatan yang melibatkan staf akademik. Penetapan matlamat program pementoran ini dikenal pasti yang memberikan banyak faedah kepada staf dan organisasi itu sendiri. Di antara kepentingan pementoran yang memberikan kesan yang positif antaranya adalah meningkatkan minat dalam kerjaya akademik (Azman et al, 2007); mempromosikan perkembangan kerjaya dan kepuasan (Friday \& Friday, 2002), meningkatkan produktiviti fakulti (Azman, 2007), menyokong prestasi kenaikan pangkat di kalangan akademia (ibid, 2007), meningkatkan keberkesanan pengajaran, penyelidikan dan perkembangan profesional (ibid, 2007) dan mengurangkan konflik antara kerjaya dan keluarga (Goldstein \& Ford, 2002). Proses pelaksanaan sistem pementoran berstrategi ini bermula dengan pemilihan pasangan mentor dan menti, pelantikan mentor dan menti, komitmen mentor dan menti, penetapan sasaran, pertemuan secara berkala, dan pemantauan serta penilaian.

Bagi objektif kedua pula, kaedah kuantitatif telah digunakan bagi mengenal pasti penerimaan staf akademik terhadap sistem pementoran berstrategi ini melalui soal selidik. Ini disokong oleh Hamidah et al (2004) yang menyatakan bahawa pendekatan kuantitatif dapat memberikan faedah kepada kajian iaitu ia dapat menghasilkan satu penemuan yang 'valid' dan 'reliable'. Abdul Ghaffar dan Mohd Najib (2003) juga menyatakan bahawa penggunaan soal selidik telah banyak digunakan kerana ia merupakan cara yang berkesan dan praktikal untuk mendapatkan maklumat. Instrumen kajian yang berbentuk borang soal selidik ini telah diadaptasikan daripada kajian Hamidah et al. (2004). Menurut Mohd Majid (2000) kajian yang dijalankan dengan menggunakan borang soal selidik adalah sesuai dengan reka bentuk kajian ini di mana penyelidikan bermatlamat untuk menerangkan fenomena yang sedang berlaku. Instrumen yang digunakan adalah berbentuk borang soal selidik yang digunakan terbahagi kepada dua (2) bahagian iaitu Bahagian A (latar belakang staf akademik) dan Bahagian B (tahap kesediaan staf akademik terhadap sistem pementoran berstrategi). Pengumpulan data dibuat melalui soal selidik menggunakan aplikasi Google Form dan diedarkan melalui aplikasi WhatsApp disebabkan oleh limitasi pergerakan kesan dari pandemik COVID-19. Penentuan dan bilangan sampel responden adalah menepati pensampelan yang telah ditetapkan oleh Krejcie dan Morgan (1970). Seramai 87 responden daripada 94 populasi pensyarah PPD SPACE UTM di Kampus Kuala Lumpur dan Johor Bahru telah terlibat. Dari segi jantina, sebanyak $74.70 \%$ staf akademik adalah perempuan dan selebihnya $25.3 \%$ adalah lelaki. Staf akademik yang tertinggi memberikan respon kepada soal selidik ini adalah dari Jabatan Geomatik dan Alam Bina iaitu sebanyak 27.00\% diikuti oleh Jabatan Pengurusan (25.30\%), Jabatan Kejuruteraan (24.10\%) dan yang terakhir adalah Jabatan Sains Komputer \& Perkhidmatan (23.00\%).

Dari segi tempoh perkhidmatan staf akademik, sebanyak $23.00 \%$ staf telah berkhidmat melebihi 10 tahun di PPD SPACE UTM. Ini bermakna, terdapat ramai calon mentor yang layak dari segi kekananan untuk memindahkan pengalaman mereka kepada staf akademik masih lagi baru berkhidmat kurang dari 10 tahun iaitu berjumlah 77.00\%. Potensi sistem pementoran secara berstrategi ini amat besar untuk dilaksanakan berdasarkan nisbah pensyarah kanan dan pensyarah muda yang ideal. Analisis yang dibuat menunjukkan bahawa $97.70 \%$ responden bersedia menerima pelaksanaan sistem pementoran berstrategi dilaksanakan di PPD SPACE UTM. 49 responden iaitu $56.32 \%$ telah menyatakan bahawa kepentingan faktor pelaksanaan pementoran berstrategi ini dapat meningkatkan keberkesanan, pengajaran, penyelidikan dan perkembangan profesional. Diikuti 25 (28.74\%) responden bersetuju pelaksanaan pementoran berstrategi ini dapat menyokong prestasi kenaikan pangkat di kalangan staf. Seterusnya $5(5.75 \%)$ responden bersetuju pelaksanaan pementoran berstrategi meningkatkan minat dalam kerjaya akademik dan 4 (4.60\%) responden setuju dengan dua (2) kepentingan ini iaitu mempromosikan perkembangan kerjaya dan kepuasan dan meningkatkan produktiviti PPD SPACE UTM. Kepentingan pementoran dapat meningkatkan keberkesanan, pengajaran, penyelidikan dan perkembangan profesional (Azman, 2007). Ini kerana, seorang mentor dapat membimbing menti untuk mengajar dengan baik dan berkesan dengan menyalurkan kemahiran dan pengalaman mentor dalam proses pengajaran dan pembelajaran kepada menti. Selain itu, mentor juga dapat membimbing menti dalam pengurusan peperiksaan dan bagaimana sistem pemarkahan kepada pelajar. Mentor juga boleh memperkenalkan menti tentang polisi, peraturan akademik, 
pekeliling akademik, prosedur-prosedur dan peraturan-peraturan lain yang berkaitan. Secara tidak langsung mentor dapat membantu menti memperkembangkan profesional.

Mentor dapat membantu menti dalam pembentukan visi dan matlamat kerjaya dan mengkaji hasil kerja menti termasuk kertas penyelidikan, dan manuskrip sebelum penghantaran ke jurnal, persidangan dan geran cadangan. Selain itu, mentor dapat membantu mengenal pasti dan mendapatkan pembiayaan melalui bantuan komunikasi yang proaktif secara penulisan dan lisan. Setelah itu, mentor membimbing menti menghasilkan cadangan penyelidikan dan membimbing menti memohon geran. Sekiranya cadangan penyelidikan atau geran tidak diterima, mentor perlu membaca ulasan-ulasan yang dinyatakan dan membimbing menti untuk memperbaikinya sebelum diserahkan kepada organisasi terbabit. Menyokong prestasi kenaikan pangkat di kalangan staf, mempromosikan perkembangan kerjaya dan kepuasan ini dapat dilihat seorang mentor membimbing menti menghasilkan log book, tugasan atau mengambil peperiksaan untuk tujuan pengiktirafan profesional. Contohnya bagi pendaftaran profesional dengan badan-badan profesional bidang masing-masing. Meningkatkan minat dalam kerjaya akademik dengan seorang menti dapat mempelajari sesuatu daripada pengalaman, kemahiran dan mencontohi cara pembelajaran mentor dalam kerjaya mentor. Menti juga boleh mendapat faedah daripada hubungan yang lebih luas dan peluang-peluang untuk bekerjasama, khidmat nasihat perancangan kerjaya, laluan untuk kritikan dan maklum balas yang jujur, nasihat tentang tanggungjawab dan keutamaan, pendedahan tentang peraturan-peraturan akademia yang formal dan tidak formal serta bantuan dalam mengembangkan kepakaran dan mendapat bahan-bahan yang diperlukan untuk berjaya.

\section{Kesimpulan}

Kesimpulannya, terdapat banyak kepentingan yang boleh diperoleh dari sistem pementoran berstrategi ini seperti meningkatkan keberkesanan pengajaran, penyelidikan dan perkembangan profesional di kalangan menti dengan bantuan dan pengawasan daripada mentor. Selain itu, dengan bantuan mentor dapat meningkatkan minat menti dalam kerjaya akademik. Sistem pementoran ini juga dapat mempromosikan perkembangan kerjaya dan kepuasan seterusnya menyokong prestasi kenaikan pangkat di kalangan mentor dan menti. Secara tidak langsung dapat meningkatkan produktiviti. Seterusnya, komitmen daripada semua staf akademik dan sokongan Pengurusan Tertinggi UTMSPACE diperlukan bagi menjayakan program pementoran berstrategi di peringkat PPD SPACE UTM.

\section{Penghargaan}

Kajian ini telah mendapat sokongan dana daripada UTMSPACE, Universiti Teknologi Malaysia di bawah Research Grant Potential Development Fund Vot No. SP-PDF2004.

\section{Rujukan}

Abdul Ghafar Mohammad (2003). Prinsip dan amalan pengajaran. Kuala Lumpur: Utusan Distributors Sdn Bhd.

Aishah Binti Mohd Sidi \& Nurul Sabrina Binti Khairuddin, (2020). Mentor-mentee: meningkatkan pencapaian dan motivasi pelajar pastri Kolej Kominiti Ledang, 852- 858.

Aladejana, A., Aladejana,F. \& Ehindero, S. (2006). An analysis of mentoring relationships among teachers: A case study of Obafemi Awolowo University, Ile-Ile, Nigeria. International Journal of Evidence Based Coaching and Mentoring, 4(1), 20-30.

Anderson, E.M. \& Shannon, A.L. (1988) Toward a conceptualization of mentoring. Journal of Teacher Education, 39, 38-42.

Azman Ismail, Kamsiah Hasbullah \& Rizal Abu Bakar (2007), Kesan pemindahan pengetahuan, kemahiran dan kebolehan ke atas amalan komunikasi dalam sistem mentoring di Institusi Pengajian Tinggi Awam. Jurnal Pendidik dan Pendidikan, 22, 133-160 
Bernier, A., Larose, S., \& Whipple, N. (2005). Leaving home for college: A potentially stressful event for adolescents with preoccupied attachment patterns. Attachment and Human Development, 7(2), $171-185$.

Debowski, S. (2012). The new academic: A strategic handbook. Maidenhead, Berkshire: Open University Press.

Friday, E. \& Friday, S. S. (2002). Formal mentoring: Is there a strategic fit? Management Decision, $40(2), 152-157$.

Goldstein, I. L. \& Ford, J. K. (2002). Training in organizations. Wadsworth: Thomson Learning.

Hamidah Abdul Rahman, Zainab Khalifah, Shoki Arif, Rosnah Sirin, Hafilah Zainal Abidin \& Norzarina Sulong (2004). Kajian mengenai tahap kualiti pendidikan tinggi dari perpektif pelajar di Universiti Teknologi Malaysia. Pusat Pengajian Penyelidikan. Universiti Teknolgi Malaysia. Monograph.

Kram KE (1985) Mentoring at work: Developmental relationships in organizational life. Scoot Foresman, Glenview, IL.

Krejcie, R.V., \& Morgan, D.W. (1970). Determining sample size for research activities. Educational and Psychological Measurement, 30, 607-610

Mohd. Majid Konting (2000). Kaedah penyelidikan pendidikan. Kuala Lumpur : Dewan Bahasa dan Pustaka.

Nakamura, J, Shernoff DJ (2009). Good mentoring: Fostering excellent practive in higher education. San Francisco: J Wiley \& Sons.

Northcott, N. (2000). Mentoring in nursing. Nursing Management, 7(3), 30-32.

Oliver, C. \& Aggleton, P. (2002). Mentoring for professional development in health promotion: A review of issues raised by recent research. Health Education, 102(1), 30-38.

Rekha NK, Ganesh PM (2012) Do mentors learn by mentoring others? International Journal of Mentoring and Coaching in Education 1(3), 205-217

Sawatzky JA, Enns CL (2009). A mentoring needs assessment: validating mentorship in nursing education. J Prof Nurs, 25(3):145-50. doi: 10.1016/j.profnurs.2009.01.003. PMID: 19450785.

Scandura, T. A. \& Williams, E. A. (2004). Mentoring and transformational leadership; the role mentoring of supervisory career mentoring. Journal of Vocational Behaviour, 65(3), 448-468.

Watkins, C. \& Whalley, C. (1993). Mentoring beginner teachers - Issues for Schools to Anticipate and Manage. School Organisation, 13(2), 129-138.

Young, A. M. \& Perrewe, P. L. (2000). The exchange relationship between mentors and proteges: The development of a framework. Human Resource Management, 10(2), 177-209. 